\title{
THE ROAD TO SUCCESS: MU'S MASTER PLAN FOR RESEARCH AND TECHNOLOGY DEVELOPMENT
}

\author{
Jack O. Burns \\ Vice Provost for Research \\ Mary M. Licklider \\ Director, Grant Writing and Publications \\ University of Missouri-Columbia
}

\begin{abstract}
"If you don't know where you're going, you might end up somewhere else." It's a truism, but it has been an apt one for too many university research endeavors over the years. So it was something of a break with the individualistic traditions of academia in 1998 when the University of Missouri-Columbia's Research Division began building on the campus-wide strategic planning process to create a Master Plan for Research and Technology Development.
\end{abstract}

We had a strong starting point in campus planning. The first goal of the campus strategic plan was (and still is) to "strength research, graduate, and professional programs and improve our stature among public AAU (the Association of American Universities) and Research I institutions." Campus priorities under this goal included increasing the diversity of the campus community, involving students in research activities, and maintaining strong lines of communication with constituencies both internal and external to the campus. In addition, several other initiatives had resulted in identification and targeting of several broad areas of research priority: special state funding for mission enhancement, the campus plan's emphasis on encouraging disciplinary strengths, and campus-level encouragement for the formation of interdisciplinary research teams.

These campus-wide goals and priorities suggested the outlines of a first Master Plan for Research and Technology Development, and this first research plan was organized around fourteen action steps. In 1999, we updated and refined that first plan, adopting six goals for research at the University of Missouri $(\mathrm{MU})$ :

$>$ Maximize internal resources and communications,

$>$ Enhance research compliance,

$>$ Provide grant assistance,

$>$ Nurture technology development,

$>$ Expand external partnerships, and

$>$ Foster governmental relations. 
These goals were further articulated in objectives and action steps, and we held ourselves accountable to these by establishing measures and assessments against which we could gauge our progress. Finally, we reported on accomplishments that had been achieved toward the action steps established in the first plan.

It is probably worth noting that the original 14 action steps had been organized under five headings: technology transfer, external partnerships, grant assistance, federal relations, and state relations. The overlap of these headings with the six goals of the last two years reflects stability in our larger priorities but not a static planning document. The original five headings saw the merger of state and federal concerns under "governmental relations"; compliance emerged as a separate goal; and more explicit attention came to be focused on internal processes. The objectives, action steps, and measures operate at a level of detail that allow the plan to be responsive to changing conditions, emerging concerns, and completed objectives. Examples from three of our goals will help illustrate how this works.

The first goal in last year's update of the Master Plan was to maximize internal resources and communications. Seven objectives supported this goal, including plans to enhance internal funding programs, improve internal and external communications, increase support for scholarship in the humanities, enhance MU's national stature, and sustain a nurturing environment for women and minorities. To track our progress toward these objectives, we established several measures: increasing funding for small internal research grants by $\$ 50,000$; increasing the number of local, state and national media stories about MU by 10 percent; adding at least one National Academy or similarly prestigious faculty member per year; and helping with campus strategies to overcome barriers to recruitment and retention of a diverse faculty. We were able to report, too, that during 1999-2000:

$>$ Federal research expenditures had risen 20 percent over the previous year (65 percent in 3 years);

$>\mathrm{NIH}$ funding had been secured to establish the MU Center for Phytonutrient and Phytochemical Studies;

> Awards in two of our most popular internal funding programs had risen nearly 70 percent over the previous year;

$>$ The Research Division had added a Faculty Fellow position to lead initiatives in the humanities;

$>$ A strategic and quality improvement plan had been developed and implemented for the Office of Sponsored Program Administration; and

$>$ "Electronic" improvements included a complete redesign of the Research Division Web site, creation of an electronic Grant Data Form for internal processing of grant proposals, and integration of the local pre- and postaward grants databases. 
Eight objectives defined the goal of providing grant assistance: developing a campus network of grant writers, increasing private foundation funding, expanding participation in the Community of Science, providing grantsmanship seminars, disseminating information about external funding opportunities, establishing externally funded centers, improving processes and services of the Office of Sponsored Program Administration, and developing and involving student teams in research. Here again, we established empirical measures that were quantitative wherever possible. We targeted a 10 percent increase in dollars requested through proposals receiving grant writer support, 95 percent faculty participation in the Community of Science; 20 percent reduction in instances of awards preceding proposals; and reduction in the mean proposal review time to less than 3 days, clinical trial implementation time to less than 45 days, and grant award implementation time to less than 2 weeks.

Accomplishments related to this goal included quantitative results and the development of a number of tools designed to clarify, speed and/or simplify external funding processes. Quantitative results included a drop in proposal review time from 21 days to 5 days and in award implementation time from 54 days to 37 days. Some of the new tools were documentary, such as template agreements and budget templates. Some were related to information access, such as creating appropriate access to the local grant database for faculty and departmental personnel. And some were training and support "tools": the enhancement of a Grants and Contracts Support Group as a means for substantive policy flow, and the addition of 2 more grant writers to the growing campus network.

Our fourth goal, nurturing technology development, is an area receiving attention on campuses across the country. For $\mathrm{MU}$, this is a relatively new priority. This novelty is reflected in objectives having to do with increasing the visibility of the new Office of Technology and Special Projects, enhancing its infrastructure, providing mentoring on technology transfer, and stimulating entrepreneurship. Other objectives are more likely to be ongoing even as the Office becomes more established: enhancing intellectual property protection and processes, promoting university research and technology to the corporate sector and economic development entities, and involving student teams in research and technology transfer. Benchmarks for this goal are also cast in quantitative terms where possible. Besides decreasing processing time for intellectual property agreements by 20 percent, we sought to increase numbers of invention disclosures by 15 percent, applications for Small Business Innovation Research and Small Business Technology Transfer by 10 percent, and cooperative agreements and licenses each by 10 percent.

Although the Office of Technology and Special Projects was only a year old, we could still report on accomplishments. During 1999-2000, besides getting the Office established and functioning, seminars were held on all four University of Missouri campuses, the organizational structure was established for the 
Missouri Seed Capital Fund, and three new companies were formed around University of Missouri technologies.

By including progress reporting and accountability measures, our plan is a very useable document for guiding day-to-day decisions of senior staff within the Research Division. We monitor our progress more formally at semi-annual, daylong retreats. The mid-year retreat is an important opportunity to monitor progress and adjust our course. The summer retreat focuses on updates and revisions. The agenda for this second retreat also includes discussion of the larger issues of how appropriate the goals and objectives are and whether any should be deleted or replaced. The Master Plan is revised and updated each year following the summer retreat. To ensure that revisions continue to accurately reflect evolving campus priorities, we seek comments and revision suggestions on draft documents from two faculty advisory committees, the Deans, Faculty Council, Provost, and Chancellor.

The resulting document presents a credible statement of purpose and action. But the Plan cannot be actualized by Research Division personnel alone. We post it on the Web. In addition, realizing that the Web is a "passive" medium that requires the reader to seek out a particular piece of information, we print hard copies and distribute them widely. All faculty receive copies, as do Missouri's Congressional delegation, local legislators, and media outlets. We use it to communicate institutional priorities to faculty recruits and others visiting campus.

By seeking input from faculty and campus administration in the development of the Master Plan but not allowing it to be bogged down in endless committee meetings, and by communicating our goals and strategies widely among the University's constituencies, we can be reasonably sure that everyone knows where we are going - which certainly raises the odds that we will get there. 